\title{
Investigation of the ignition of wood structural materials (with and without fire retardant treatment) under the influence of a model fire of irregular intensity
}

\author{
Denis Kasymov ${ }^{*}$, Mikhail Agafontsev, Vladislav Perminov, and Pavel Matrynov \\ National Research Tomsk State University, 36 Lenin Ave., Tomsk, Russia 634050
}

\begin{abstract}
In this paper the effect of fire front on the surface of wood samples (plywood and oriented strand board) was considered to estimate the effect of different wood-fire retardants. Infrared thermography was used as a diagnostic method. The ignition probability was estimated for the chosen experimental parameters for each kind of wood The fire hazard characteristics of wood after fire retardant treatment showed a significant reduction in the surface temperature and the resistance to fire for the chosen parameters of the experiment compared to the same untreated samples. The charring depth of the wood samples was determined depending on the type of wood, as well as on the type of the fire retardant used.
\end{abstract}

\section{Introduction}

In recent years, there has been an increase in the number of wildland-urban interface fires. The ignition of buildings in the wildland-urban interface is a serious international problem due to large-scale fires in Australia, Greece, Portugal, Russia and the USA. In Russia, where forests occupy a large territory, the wildland-urban interface fires are a national problem, and the damage to the real sector of the economy is tens and hundreds of millions of dollars per year. For example, the destructive fires occurred in 2015 (Russia, the Republic of Khakassia), as a result, several settlements were completely burnt out for a short time.

The investigation of initiation, propagation and suppression of wildland fires is still an urgent problem due to huge environmental and economical losses. Despite the measures taken to prevent fire-hazardous situations, the annual number of fires remains quite high. The fire protection of buildings requires scientific developments based on experimental studies to determine the lows of ignition and burning of buildings exposed to thermal flows of model wildland fires.

In the literature there are a lot of experimental studies concerning the fire hazard of wood, which demonstrate the influence of various factors on the fire hazard indices (species of wood, conditions and duration of operation, humidity, fire intensity, etc.). These studies

\footnotetext{
*Corresponding author: denkasymov@gmail.com
} 
are represented by the works of [1-9]. In these works the pyrolysis and thermal oxidative degradation of wood are studied, thermal and physical characteristics are determined, and the values of carbonization rates are obtained for various temperature modes. These data can be used to evaluate the fire resistance of wooden structures, but most of the methods applied to assess the fire hazard of wood are referred to contact methods (micro thermocouple techniques, molecular-beam mass spectrometry, thermal analysis methods, etc.). Contact methods are often used for recording temperature fields, heat fluxes, carbonization rates, ignition delays, etc. to model combustion processes under laboratory conditions; however, a large number of thermocouples are required to record temperature fields under field and semi-field conditions, which causes difficulties for processing the results.

At present, thermal imaging equipment is not often used in the study of wildland fires, since this phenomenon depends on a large number of parameters and requires a detailed study of a radiation coefficient. It should be noted that information on the application of contactless methods in the fire tests of building fragments and structures [10], as well as the application of IR thermography in the study of urban and peat fires [11-12] is still absent in the literature. Contact methods are the traditional methods for measuring the temperature during fire-engineering tests of building structures.

The main problem in the operation of wood materials is their susceptibility to decay, the appearance of fungi and mold. However, besides this, a high degree of danger is inflammability. One of the ways to reduce the flammability of artificial and natural polymer materials (including wood) is the use of flame retardants, that can be introduced into polymer during the production of materials or deposited on polymer during the surface treatment of finished products.

In this paper, the effect of various flame retardants was evaluated to study the influence of the fire front on the surface of wood building material samples [13-14]. The IR thermography was used as a diagnostic method [15].

\section{Methodology of the experiment}

Combustion, simulated by forest fuel (FF), consisted of pine needles (Pinus Pinaster) and represented a site with a width that was close to the size of the wood sample. The dimensions of the samples in the experiment were (Length $\times$ Width $\times$ Height): $0.300 \times$ $0.016 \times 0.300 \mathrm{~m}$ for plywood, $0.300 \times 0.018 \times 0.300 \mathrm{~m}$ for oriented strand board. The densities of materials depending on the thickness are $570-590 \mathrm{~kg} / \mathrm{m}^{3}$ for OSB samples with width range $0.018-0.025 \mathrm{~m} ;=650-690 \mathrm{~kg} / \mathrm{m}^{3}$ for plywood samples with width range $0.015-0.016 \mathrm{~m}$.

Figure 1 shows a schematic diagram of the experiment:
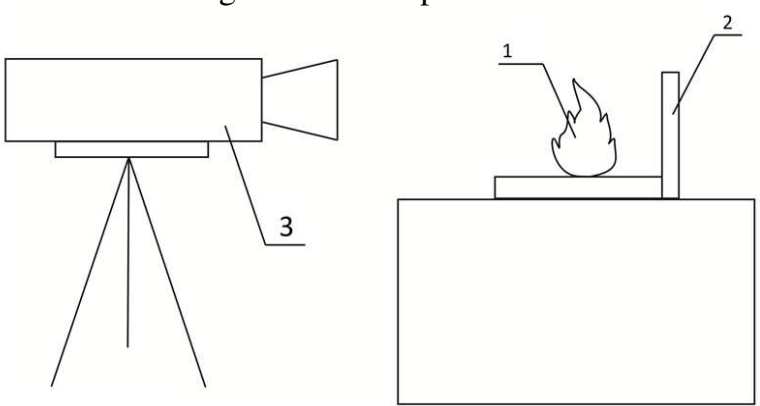

Fig. 1. Experimental setup. 1 - site with FF, 2 - wood sample, 3 - thermal imager JADE J530SB. 
The method presented in [14-15] was used to determine the temperature fields on the surface of the studied wood samples subjected to the model forest fire by applying a noncontact method. In addition, along with the «FUKAM» fire-bio retardant treatment for wood [16], the following solutions were considered: «Pirilax-Classic» fire retardant treatment with an antiseptic effect for wood [17], «SENEZH OGNEBIO PROF» fire retardant [18], as well as «MIG-09» fire-retardant composition [19].

The consumption of fire-retardant compositions, as determined by the manufacturer's technical specifications, guaranteed the II group of fire-retardant efficiency in accordance with GOST R53292 [20]. The sample surface that was subjected to the thermal action of the combustion front was uniformly coated by a flame retardant composition with a brush. The samples were kept for 24 hours and then were placed in a drying oven ShSP-0.5-200 at a temperature of $70^{\circ} \mathrm{C}$ until the moisture content was $W=2 \%$. The FF mass maintained constant and was $150 \mathrm{~g}$ in the experiment, thus modeling a ground fire of weak intensity. The model of a ground forest fire of low intensity was used, since this fire was the most widespread in the natural environment, the modeling of which under laboratory conditions did not require significant maintenance costs.

Figure 2 shows a photograph of the building material samples used in experiment.

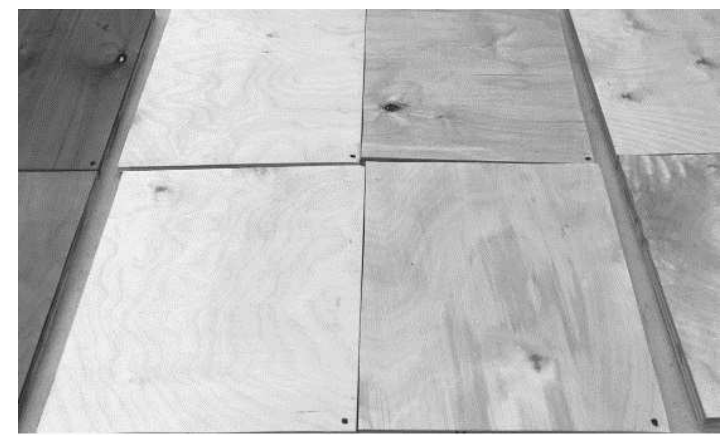

Fig. 2. Wood samples.

\section{Results and discussion}

The use of the non-contact method allowed us to obtain the distribution of the temperature fields on the surface of the sample subjected to the combustion source.

The analysis of the data obtained for untreated wood shows that the larch samples are resistant to ignition for the selected experimental parameters. The other samples (pine, aspen) [21-22], irrespective of geometry, are ignited by the combustion source. Figure 3, as an example, shows the thermograms of untreated plywood (Figure 3(a)); plywood sample treated by fire retardant «SENEZH OGNEBIO PROF» (Figure 3(b)); untreated oriented strand board (Figure $3(\mathrm{c})$ ); oriented strand board treated by fire retardant «SENEZH OGNEBIO PROF» (Figure 3(d)). 


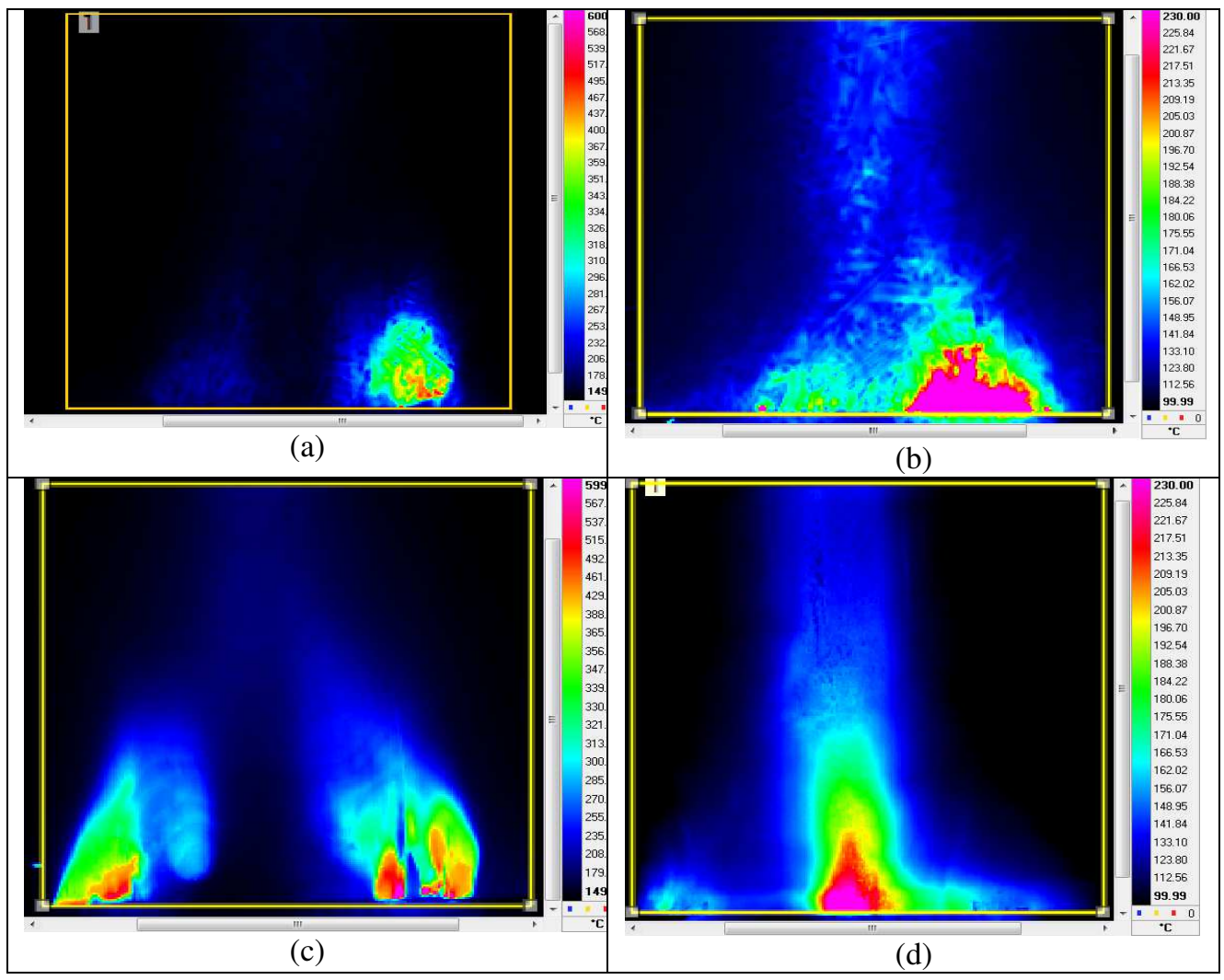

Fig. 3. Thermograms of sample surfaces after fire exposure.

The geometric dimensions of the most high-heat areas were measured using tools available in the Altair software. The size of the sites was determined at the time when the burning layer of forest fuels completely burned out and the flame stopped screening the area under study. For the chosen experimental parameters the surface of the wood samples became charred, but flame combustion was observed only in a few cases, which appears to be connected to the small capacity of the heat flow, as well as the short duration of its effect on wood.

The thermograms obtained are processed as follows. The rectangular area containing the sample surface was selected and covered with the straight horizontal lines in the thermogram (Figure 4), using the Altair software. 


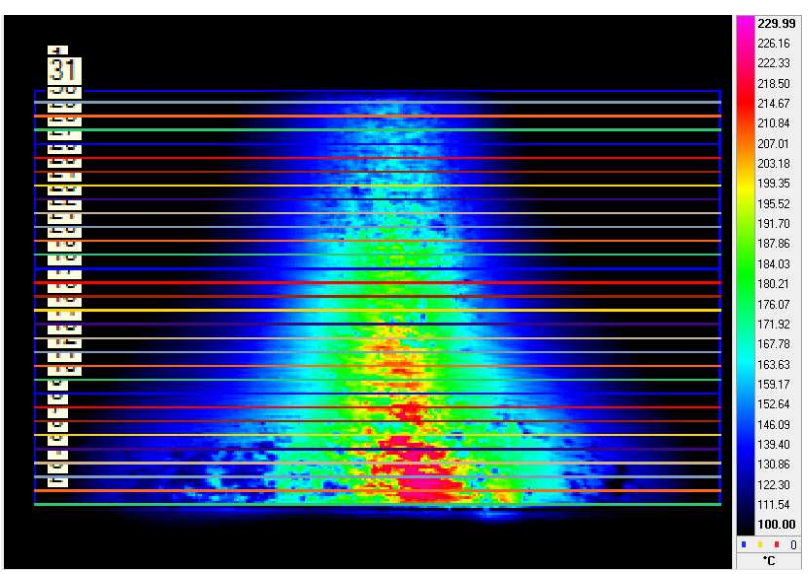

Fig. 4. Examples of thermograms of sample surfaces with installed measuring instruments after fire front exposure.

The distance between the lines was 3 pixels, which corresponded to $1.8 \mathrm{~mm}$ on the sample. The height of the line corresponded to the size of the sample. The temperature column determined in each pixel of the corresponding straight line was obtained for each straight line. As a result, knowing the geometrical position of the straight lines and the temperature values, the graphs of the temperature distribution on the surface of the test sample were obtained for the different time intervals.

The processed thermal imaging data obtained in the experiment are listed in Table $1 . *_{-}$ Averaging over three experiments.

Table 1. The values of the maximum temperature $T_{\max a v}$ on the surface of the wood samples, depending on the fire retardant used.

\begin{tabular}{|l|c|c|}
\hline Wood samples & Fire-retardant compositions & $\boldsymbol{T}_{\text {max }}{ }^{{ }^{*}}{ }^{*}{ }^{\mathbf{0}}{ }^{\mathbf{C}}$ \\
\hline \multirow{4}{*}{ Plywood } & «Pirilax Classsic» & 247 \\
\cline { 2 - 3 } & «SENEZH OGNEBIO PROF» & 209 \\
\cline { 2 - 3 } & «MIG-09» & 218 \\
\cline { 2 - 3 } & «FUKAM» & 228 \\
\cline { 2 - 3 } & Without treatment & 663 \\
\hline \multirow{4}{*}{ Oriented strand board (OSB) } & «Pirilax Classsic» & 574 \\
\cline { 2 - 3 } & «SENEZH OGNEBIO PROF» & 468 \\
\cline { 2 - 3 } & «MIG-09» & 365 \\
\cline { 2 - 3 } & «FUKAM» & 462 \\
\cline { 2 - 3 } & Without treatment & 584 \\
\hline
\end{tabular}

In addition, the software for working with the thermal imager allowed us to estimate the cooling time of wood samples as a result of the combustion source. In is interested to compare the characteristic cooling times for samples treated with flame retardant. Table 2 shows the characteristic cooling times of the oriented strand board (OSB) and plywood, as well as the dimensions of the heat-stressed areas, whose geometric dimensions were analysed based on the results of the IR-detection. * - Averaging over four experiments. It should be noted that due to the nature of the structure of the wood materials under consideration (the presence of various adhesive residues in the material, porosity), the thermal effect from the fire front and the corresponding cooling time of the samples differ 
significantly in the same series of experiments. An additional number of experiments will further allow to refine the results.

Table 2. Cooling time of wood samples.

\begin{tabular}{|c|c|c|c|c|c|c|}
\hline \multirow{2}{*}{$\begin{array}{l}\text { Flame } \\
\text { retardant }\end{array}$} & \multicolumn{2}{|c|}{ Cooling time } & \multicolumn{4}{|c|}{ Dimensions of the heat-stressed areas } \\
\hline & $t, \mathrm{~s}$ & $t^{*}, \mathrm{~s}$ & $X, \mathrm{~mm}$ & $Y, \mathrm{~mm}$ & $X^{*}, \mathrm{~mm}$ & $Y^{*}, \mathrm{~mm}$ \\
\hline \multicolumn{7}{|c|}{ Oriented strand board (OSB) } \\
\hline \multirow{4}{*}{ No treatment } & Ignition** & \multirow{4}{*}{80,5} & 55 & 33 & \multirow{4}{*}{33,5} & \multirow{4}{*}{35,4} \\
\hline & Ignition $* *$ & & 28 & 46,31 & & \\
\hline & 87 & & 21,25 & 40,37 & & \\
\hline & 74 & & 31,41 & 25,36 & & \\
\hline \multirow{4}{*}{ «Pirilax» } & 64 & \multirow{4}{*}{43} & 25,50 & 61,76 & \multirow{4}{*}{45,2} & \multirow{4}{*}{50,4} \\
\hline & 40 & & 50 & 35 & & \\
\hline & 32 & & 40 & 50 & & \\
\hline & 37 & & 61 & 30 & & \\
\hline \multirow{4}{*}{$\begin{array}{c}\text { «ENEZH } \\
\text { OGNEBIO } \\
\text { PROF» }\end{array}$} & 30 & \multirow{4}{*}{33,5} & 67 & 48 & \multirow{4}{*}{62,75} & \multirow{4}{*}{49,25} \\
\hline & 35 & & 40 & 40 & & \\
\hline & 37 & & 78 & 55 & & \\
\hline & 32 & & 66 & 54 & & \\
\hline \multirow{4}{*}{ «MIG-09» } & 26 & \multirow{4}{*}{42} & 51 & 43 & \multirow{4}{*}{59} & \multirow{4}{*}{53} \\
\hline & 31 & & 60 & 54 & & \\
\hline & 24 & & 55 & 57 & & \\
\hline & 90 & & 70 & 58 & & \\
\hline \multirow{4}{*}{ «FUKAM» } & 34 & \multirow{4}{*}{25} & 69 & 78 & \multirow{4}{*}{64,75} & \\
\hline & 15 & & 91 & 73 & & \\
\hline & 20 & & 48 & 27 & & 56,5 \\
\hline & 31 & & 51 & 48 & & \\
\hline Flame & cooli & & & nsions of th & heat-stresse & reas \\
\hline retardant & $t, \mathrm{~s}$ & $t^{*}, \mathrm{~s}$ & $X, \mathrm{~mm}$ & $Y, \mathrm{~mm}$ & $X^{*}, \mathrm{~mm}$ & $Y^{*}, \mathrm{~mm}$ \\
\hline & & & ood & & & \\
\hline & Ignition** & & $\begin{array}{c}31,24, \\
18\end{array}$ & $31,43,42$ & & \\
\hline No treatment & Ignition** & 122,5 & 48 & 49 & 39,3 & 51,6 \\
\hline & Ignition** & & 66 & 73 & & \\
\hline & 25 & & 49 & 72 & & \\
\hline & 28 & & 48 & 27 & & \\
\hline «Pirilax» & 20 & & 31,54 & 42,21 & & \\
\hline & 33 & 29 & 54 & 51 & 48,4 & 42,6 \\
\hline & 35 & & 55 & 70 & & \\
\hline «SENEZH & 41 & & 87 & 36 & & \\
\hline OGNEBIO & 45 & 13 & 67 & 45 & & \\
\hline PROF» & 35 & 43 & 42,52 & 39,43 & 64,2 & 47,8 \\
\hline & 51 & & 73 & 76 & & \\
\hline & 21 & & 48 & 46 & & \\
\hline & 32 & 32 & 45,51 & 37,30 & & \\
\hline «MIG-09» & 34 & 32 & 58,42 & 30,31 & 50,1 & 32,5 \\
\hline & 42 & & 57 & 21 & & \\
\hline & 36 & & 39 & 21 & & \\
\hline FUUKAM & 27 & 325 & 58 & 25 & 435 & 36 \\
\hline «FUKAM» & 40 & 33,5 & 37 & 61 & 43,5 & 36 \\
\hline & 31 & & 40 & 36 & & \\
\hline
\end{tabular}


* - In this case, the sample was ignited and did not decay during the experiment. $t$ - cooling time; X, Y - length and width of the heat-stressed areas.

\section{Conclusions}

The effect of the various fire-retardant compositions (fire-bio retardant treatment for wood «FUKAM», fire-retardant treatment with an antiseptic effect for wood «Pirilax-Classic», protective means for wood «SENEZH OGNEBIO PROF», and fire-retardant composition «MIG-09») was experimentally analyzed to study the fire-hazard characteristics for the wood samples. Comparative analysis shows that depending on the kind of wood the best fire-retardant characteristics are demonstrated by different compositions such as the protective means for wood «SENEZH OGNEBIO PROF» for the plywood and fireretardant composition «MIG-09» for the oriented strand board.

Using the experimental data obtained, high-heat areas were found on the surface of wooden model structures exposed to the forest ground fire. The characteristic size of found areas was: $53 \times 49 \mathrm{~mm}$ for oriented strand board (OSB), $49 \times 42 \mathrm{~mm}$ for plywood.

For the chosen parameters of the experiment and the thermal energy released during the combustion of plant fuels in the amount of $150 \mathrm{~g}$ on the site (assuming $0.172-0.263 \mathrm{~kg} / \mathrm{m}^{2}$ ), the ignition of wood samples was not observed. For a sample of building pine board covered with fire-retardant "Pirilax Classsic", short ignition was observed on the surface; however when plant fuels burned out completely, combustion stopped.

This study was supported by the Russian Science Foundation (project No. 18-79-00232).

\section{References}

1. J. Schmid, M. Klippel, A. Just et al., Fire Technol 54: 1113 (2018)

2. A. Frangi, M. Fontana, E. Hugi, and Jubstl, Fire Safety J. 44, 1078-87 (2009)

3. A.M. Grishin, A.I. Filkov, E.L. Loboda et al., Int. J. of Wildland Fire 23, 445-49 (2014)

4. A.B. Sivenkov, R.M. Aseeva, and B.B. Serkov, Combustion of wood and its fire hazard properties. Academy of State Fire Service of the Ministry of Emergency Measures of Russia, 262 (2010)

5. P. Reszka and J.L. Torero, Exp Therm Fluid Scie 32, 1405-11 (2008)

6. V. Babrauskas, Fire Safety J. 40, 528-54 (2005)

7. B. Östman, D. Brandon, H. Frantzich, Fire Safety J. 91, 11-20 (2017)

8. A.I. Bartlett, R.M. Hadden, L.A. Bisby, and A. Law, XIV Int. Conf. and Exhibition, Proc. Fire and Materials, 667-81 (2015)

9. V.T. Kuznetsov and A.I. Fil'kov, Combust Explos Shock Waves 47, 65-69 (2011)

10. V.S. Mel'nikov, I.R. Hasanov, S.V. Kirillov et al., Fire Safety J. 3, 83-90 (2015)

11. I. Vermesi, J.M. Didomizio, F. Richter et al., Fire Safety J. 91, 218-25 (2017)

12. N. Prat-Guitart, C.M. Belcher, R. Hadden et al., Coal and peat fires: A global perspective 121-39 (2015)

13. V.P. Zima and D.P. Kasymov, J Eng Phys Thermophy 89, 466-70 (2016)

14. D. Kasymov and M. Agafontsev, EPJ Web Conferences 159, 1-5 (2017)

15. V.P. Vavilov Thermal/Infrared Nondestructive Testing (NDT Handbooks series) 5450. (2009) 
16. The special substance for processing different fabrics and building materials «FUKAM», http://www.fukam.ru/English/

17. The special substance for processing different fabrics and building materials "Pirilaks", https://www.nort-udm.ru/en/

18. Means protective for wood, instruction on application, http://www.strsezon.ru/ognebio_prof.pdf

19. The special substance for processing different fabrics and building materials "Mig09", https://www.nort-udm.ru/en/

20. Fire-retardant compounds and substances for wood and materials based on it. General requirements. Test methods. Moscow FRUP "Standartinform", http://bpl32.ru/bank/normativnye-dokumenty/gost-r-53292.pdf

21. M.V. Agafoncev and D.P. Kasymov, Actual problems of thermophysics and physical hydrodynamics 81-2 (Novosibirsk, 2016)

22. M.V. Agafoncev and D.P. Kasymov Proceedings of the VIII European Combustion Meeting (Dubrovnik, Croatia, 2017) 